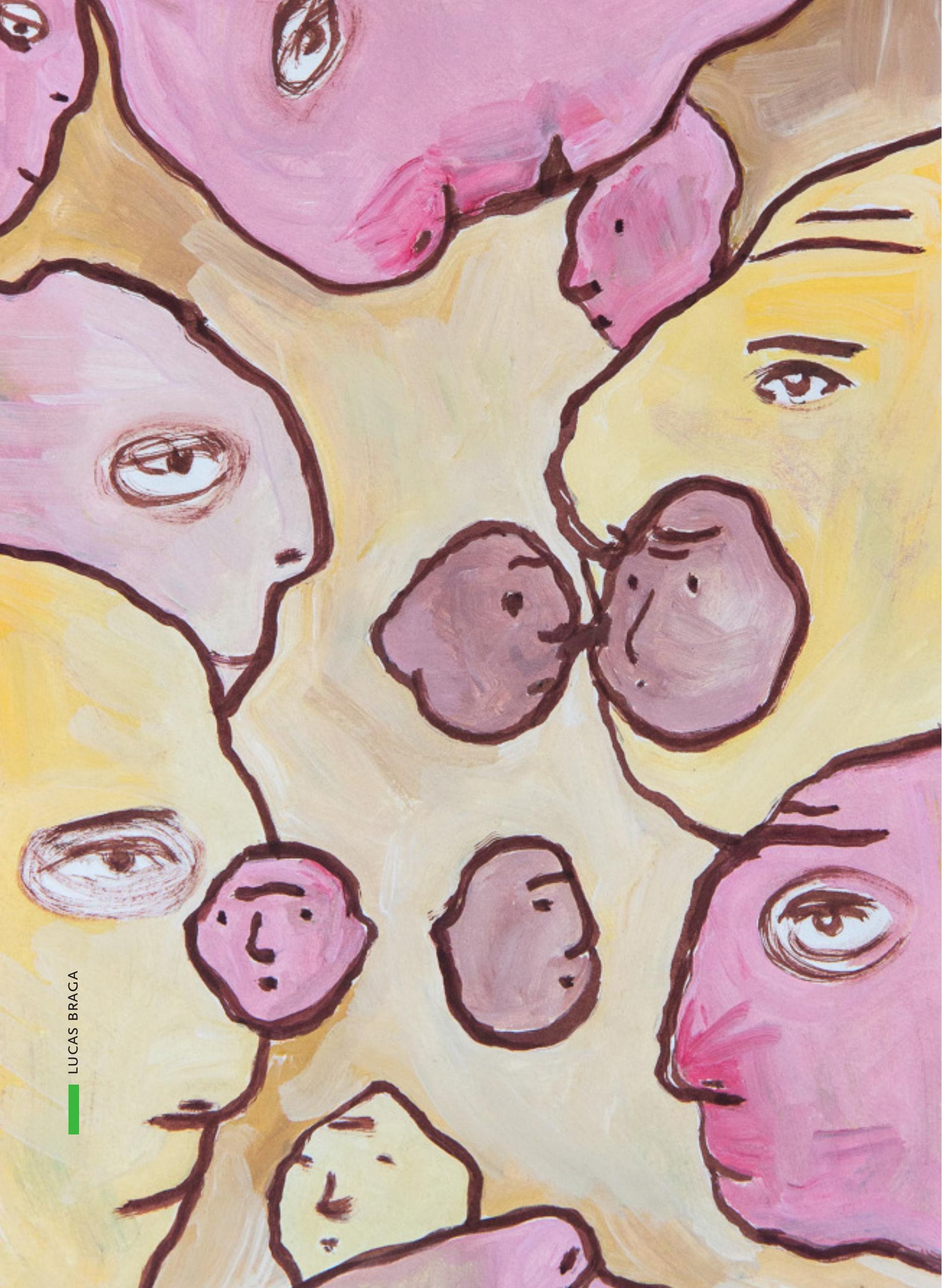




\section{DARWIN E MARX, DURKHEIM E WEBER: relações entre a forma de pensar evolução na Biologia e na Sociologia}

\section{BRUNAH SCHALL*}

RESUMO O pensamento evolutivo é de grande importância na Biologia e na Sociologia, pois em ambas as disciplinas há uma tentativa de compreender as mudanças que ocorrem ao longo do tempo, na natureza e na sociedade. Com foco nesse tipo de pensamento, é possível delinear interseções entre a teoria da evolução por seleção natural de Darwin e as ideias de Karl Marx, Émile Durkheim e Max Weber, comparando os tipos de perspectivas históricas desenvolvidas por cada um. A discussão dessas interseções pode contribuir para uma melhor compreensão e ensino das disciplinas, fomentando visões transdisciplinares e críticas que as enriquecem, advertindo também para possíveis interpretações ideológicas que têm impacto sobre a realidade.

Palavras-chave Pensamento evolutivo. Biologia. Sociologia

\section{DARWIN AND MARX, DURKHEIM AND WEBER: relationships between the ways of thinking evolution in Biology and in Sociology}

ABSTRACT The evolutionary thought is of great importance in Biology and Sociology because in both disciplines there is an effort to understand the changes that occur along time, both in nature and society. With a focus on this kind of thought, it is possible to identify intersections between Darwin's theory of evolution by natural selection and the ideas of Karl Marx, Émile Durkheim and Max Weber, comparing the types of historical perspectives developed by each of them. The discussion of these intersections can contribute to a better understanding and teaching of the disciplines, fostering transdisciplinary and critical views that enrich them, also alerting to possible ideological interpretations that impact reality.

KEYWORDS Evolutionary thought. Biology. Sociology.

* Bióloga e Mestre em Sociologia pela Universidade Federal de Minas Gerais (UFMG)

E-mail: brunah.schall@gmail.com

Recebido em 31/07/2014. Aprovado em 08/08/2014. 


\section{Introdução}

rande parte da reflexão filosófica e científica desde os primórdios até os tempos

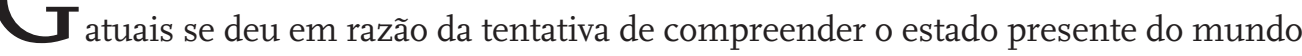
e da humanidade com baese no passado e, em alguns casos, tendo em vista reduzir as incertezas sobre o futuro. A percepção humana sobre a passagem do tempo e as mudanças no transcorrer da história levou a perguntas principalmente sobre onde, por que e como ocorrem transformações ou quais seriam as suas causas e consequências. No campo da biologia, é possível identificar essas perguntas na teoria da evolução de Charles Darwin. Na sociologia, Karl Marx, Émile Durkheim e Max Weber faziam questionamentos semelhantes. Onde está a mudança, no individual e/ou no coletivo (espécie ou sociedade)? Por que ela acontece, ou qual sua causa e consequência, progresso, conflito, acaso? Ela acontece por meio de adaptação, mutação ou seleção? Algumas vezes de forma consciente, outras não, os pensadores referidos partiram das mesmas perguntas e chegaram a conclusões similares em suas respectivas áreas. Traçar paralelos entre suas formas de pensar pode levar a uma melhor compreensão de suas ideias.

\section{Indivíduo ou população, agência ou estrutura}

Ao estudar a história dos seres vivos ou da sociedade, surge a pergunta sobre onde ocorre a mudança observada ao longo do tempo, ou qual é a sua direção: das partes para o todo ou do todo para as partes. Há uma polarização entre ênfases micro e macro: indivíduo ou população (Biologia) e agência ou estrutura (Sociologia). Apesar da existência de tentativas de integrar esses polos em teorias unificadoras, muitas vezes dialéticas, a maioria das pesquisas prioriza um dos lados. Na Sociologia, Durkheim e Weber geralmente são vistos como precursores de metodologias opostas: enquanto o primeiro defendia o estudo dos fatos sociais, observados no todo, o segundo reforçava 
a importância do sentido subjetivo, observado nas partes. Já na Biologia, Darwin é o divisor de águas; antes da publicação de A Origem das Espécies, a maioria dos estudos tinha o indivíduo como foco. De modo geral, as ideias evolutivas do século XIX, diferentes das de Darwin, como a teoria da transmissão dos caracteres adquiridos por uso e desuso de Jean-Baptiste Lamarck, supõem que o indivíduo se adapta ao meio de maneira ativa, e a mudança da população ocorre devido à soma de transformações individuais. Darwin, por outro lado, propôs uma explicação selecional ${ }^{\mathrm{I}}$, segundo a qual o meio não provoca o aparecimento de novas características, mas seleciona naturalmente (e não ativamente, de maneira racional ou metafísica) indivíduos que apresentam de antemão uma determinada variação dentro de uma população, alterando assim a composição desta. Para o naturalista, a mudança da população não ocorre devido a uma soma de mudanças individuais independentes, mas em razão de uma transformação coletiva e conectada pelas relações estabelecidas entre os membros dessa população.

Durkheim explica de maneira clara e objetiva essa ideia em As Regras do Método Sociológico, "Ele [fenômeno coletivo] está em cada parte porque está no todo, o que é diferente de estar no todo por estar nas partes” (Durkheim, 2007, p. ०9). Ao diferenciar "classe em si” de "classe para si”, Marx parece também refletir sobre essa questão. A "classe em si” seria a simples soma de partes iguais, que não forma necessariamente um todo e não promove mudanças. Segundo Marx, somente a “classe para si” é capaz de liderar uma revolução, pois nesse caso o grupo não é apenas a soma de indivíduos iguais, já que há uma identidade coletiva formada pelo complexo de relações dentro do grupo.

Já Weber parece seguir outra direção ao ressaltar a importância de líderes carismáticos, que sozinhos são capazes de conduzir grandes mudanças sociais. No entanto, as lideranças não surgem isoladamente de um contexto. Em A ética protestante e o “espírito” do capitalismo, Weber parece compartilhar do pensamento de Darwin sobre o fato de a mudança se apresentar como um conjunto e não como uma soma de transformações individuais:

Para que essas modalidades de conduta de vida e concepção de profissão adaptadas à peculiaridade do capitalismo pudessem ter sido "selecionadas", isto é, tenham podido sobrepujar outras modalidades, primeiro elas tiveram que emergir, evidentemente, e não apenas em indivíduos singulares isolados, mas sim no modo de ver portado por grupos de pessoas (WEBER, 2005, p. 48). 
Na pesquisa biológica ou sociológica, a mudança de foco do individual para o coletivo levou a um incômodo quanto à passividade ou a falta de poder do indivíduo sobre o seu destino. Nas ideias transformistas anteriores a Darwin, o indivíduo tinha o poder de se adaptar ao meio e assim progredir por vontade e esforço próprios no curso da evolução. Com a seleção natural não há mais esse poder; cada um está sujeito a regras maiores do que a sua percepção, as quais estão fora de seu controle, pois envolvem um conjunto muito grande de fatores interligados de maneira complexa e imprevisível, ao acaso. Porém, apesar da coletividade ser considerada a protagonista da história, a singularidade tem um papel importante na mudança, pois essa não aconteceria no âmbito social ou biológico se todos fossem iguais. É necessário identificar, portanto, o que faz a mudança transcender do plano individual para o coletivo, no qual ela passa a ter significado histórico relevante. Na biologia e na sociologia, esse elemento conectivo entre parte e todo foi identificado principalmente por Darwin e Marx como sendo o conflito, a luta pelos recursos do meio.

\section{Luta pela sobrevivência e luta de classes}

A luta pela sobrevivência e a luta de classes é, ao mesmo tempo, um ponto em comum e de discordância entre Marx e Darwin. Ambos detectam o conflito como “o motor da história”, porém discordam quanto à necessidade de que esse conflito exista sempre para que a história continue a progredir. Ao ler A Origem das Espécies, Marx escreve a um amigo: "O livro de Darwin é muito importante e me serve como base natural-científica para a luta de classes na história” (Werkr, apud Gerratana, I974, p.

2. "Darwin's book is very important and serves me as a natural-scientific basis for the class struggle in history.
63, tradução nossa) ${ }^{2}$. Há, inclusive, rumores de que Marx pretendia dedicar o segundo volume de O Capital (I885) a Darwin, que teria recusado a homenagem em uma carta, a qual fora encontrada entre documentos de Marx. No entanto, acredita-se que a carta era na verdade endereçada a Edward Aveling, um biólogo inglês, genro de Marx, que gostaria de dedicar a Darwin o segundo volume de seu livro Student's Darwin (I88I). Segundo historiadores, apesar de Marx inicialmente ter recebido bem as ideias de Darwin, sua opinião sobre a teoria da seleção natural se tornou ambígua e confusa, pois a encarava ao mesmo tempo como um reflexo do pensamento burguês e, pelo menos até certo ponto, como uma verdade científica (Colp, I982, p. 48I). Marx defendia que Darwin havia detectado na natureza um mecanismo de mudança semelhante ao en- 
contrado por ele na história da humanidade. Porém, ele era contra a ideia comum entre economistas de que o modo de produção burguês, baseado na livre competição, deveria ser considerado uma lei natural eterna, e não histórica:

[...] mistas dão a entender que se trata de relações pelas quais se cria a riqueza e se desenvolvem as forças produtivas, em conformidade com as leis da natureza. Portanto, tais relações são elas próprias leis naturais independentes da influência do tempo. São leis eternas que devem reger sempre a sociedade. Assim, já houve história, mas agora deixou de haver. (MARX in BOURDIEU et al., I999, p. I47).

Darwin assume, como os economistas, que é preciso haver sempre uma luta pela sobrevivência, ou seja, competição, para que o homem continue a se desenvolver. Porém, ele não estava assim defendendo o livre comércio dos economistas. O que ele pregava era que as taxas naturais de aumento populacional não fossem muito diminuídas, como propunha Thomas Malthus, pois, sem um grande número de indivíduos, não há competição. É preciso que nasçam mais pessoas do que a natureza é capaz de acordo com suas vontades. sustentar para que aquelas com melhores características possam ter vantagem sobre as outras e se tornem predominantes. Em A Descendência do Homem (I9OI) ele escreve:

O homem, como qualquer outro animal, sem dúvida, avançou à sua presente condição superior por meio de uma luta pela existência consequente de sua rápida multiplicação; e se ele vai avançar ainda mais, é de se temer que ele deva permanecer sujeito a uma severa luta. Caso contrário, ele irá afundar na indolência, e homens com melhores características não iriam ter mais sucesso que os outros na batalha pela vida. Assim, nossa taxa natural de crescimento, apesar de levar a vários e óbvios males, não deve ser grandemente reduzida de maneira alguma (tradução nossa, DARWIN in GERRATANA, I974, p. 75) ${ }^{3}$

Ao aplicar diretamente sua teoria ao homem, Darwin não leva em conta a própria evolução humana, que demonstra ser o homem capaz de sobrepujar a natureza de acordo com suas vontades. Ele não está submetido à lei natural como qualquer outro ser vivo, pois sua consciência lhe permite desafiar os limites do que lhe é imposto pelo mundo natural, adaptando o ambiente a si mesmo. Como ironiza Engels:
3. "Man, like every other animal, has no doubt advanced to his present high condition through a struggle for existence consequent on his rapid multiplication; and if he is to advance still higher, it is to be feared that he must remain subject to a severe struggle. Otherwise he would sink into indolence, and the more gifted men would not be more successful in the battle of life than the less gifted. Hence our natural rate of increase, though leading to many and obvious evils, must not be greatly diminished by any means" (DARWIN in GERRATANA, 1974, p. 75). 
4."Darwin did not know what a bitter satire he wrote on mankind, and especially on his countrymen, when he showed that free competition, the struggle for existence, which the economists

celebrate as the highest historical achievement, is the normal state of the animal kingdom. Only conscious organization of social production, in which production and distribution are carried on in a planned way, can lift mankind above the rest of the animal world as regards the social aspect, in the same way that production in general has done this for men in their aspect as species." (Dialectics of Nature, 1883, p. 35. In GERRATANA, 1974, p. 75).
Darwin não sabia que amarga sátira havia escrito sobre a humanidade e especialmente sobre seus compatriotas, quando mostrou que a livre competição, a luta pela existência, que os economistas celebram como a maior conquista histórica, é o estado normal do reino animal. Apenas a organização consciente da produção social, na qual a produção e a distribuição são levadas de maneira planejada, pode levantar a humanidade acima do resto do mundo animal quanto ao aspecto social, da mesma forma que a produção em geral elevou o homem no seu aspecto como espécie (tradução nossa, Dialectics of Nature, I883, p. 35. In GERRATANA, I974, p. 74) ${ }^{4}$

Para Marx e Engels, Darwin, sem perceber, demonstrou que, ao seguir o modo de produção burguês, o homem se coloca no mesmo nível dos outros animais. Portanto, esse modo de produção não é o topo mais alto de uma escala de progresso evolutivo, como defendem os economistas, mas é a base de qualquer organização de seres vivos. Somente quando o homem planeja o seu modo de produção de maneira racional, a condição humana se eleva e se liberta de sua animalidade, afirmam os dois. Sendo o homem capaz de ativamente transformar a si mesmo e o mundo a sua volta, sem se deixar domar pela natureza, a história humana não corre o risco de estagnar devido à ausência de competição. Segundo Marx, diferentemente do animal "que produz apenas o que precisa imediatamente para si ou seu filhote", o homem "produz mesmo livre da necessidade física e só produz verdadeiramente sendo livre da mesma”, ele “também forma segundo as leis da beleza” (Marx, I983, p. 157). Assim, o caminho da humanização, para esses teóricos, seria a sociedade comunista, na qual não haveria mais conflito entre os homens e entre eles e a natureza, pois nesse tipo de sociedade os homens poderão:

[...] assumir a direção da produção, orientando-a, segundo sua vontade consciente e suas necessidades, e não de acordo com um poder "externo" que regule a atividade que caracteriza a espécie. (QUINTANERO et al., 2003, p. 53)

\section{Progresso ou acaso}

A questão da superioridade humana em relação aos outros animais constitui outro ponto de divergência entre o pensamento de Marx e Durkheim e o de Darwin: a concepção de evolução como progresso. O homem para Darwin não é o maior exemplo de perfeição ou o ápice de uma escala evolutiva progressista, do simples para o complexo. 
Marx, por sua vez, aplica o conceito de progresso em seus estudos sobre a evolução dos modos de produção, assim como Durkheim identifica uma escala de progresso ao estudar a história da divisão do trabalho e da vida religiosa. Esse tipo de pensamento progressista era comum à grande maioria de cientistas do século XIX, influenciados pelo contexto dos grandes desenvolvimentos da Marx, por sua vez, aplica o Revolução Industrial. Darwin, entretanto, não usou a palavra "evolução" em seu trabalho, que em sua época estava "firmemente ligada ao conceito de progresso" (Gould, I999, p. 26). Esse termo foi introduzido por Herbert Spencer e passou a ser largamente adotado pelos cientistas que "precisavam de uma palaconceito de progresso em seus estudos sobre a evolução dos modos de produção, assim como Durkheim identifica uma escala de progresso ao estudar a história da divisão do trabalho e da vida religiosa vra mais sucinta para a descendência com modificação de Darwin” (Gould, I99, p. 28). Além disso, a maioria deles acreditava no progresso em direção a formas complexas ao longo do tempo, apesar de defenderem que, no início da vida, existiam formas simples e que, ao longo da história, surgiram estruturas mais complexas. Darwin esclarece que essa mudança nem sempre representou um progresso. Muitas estruturas complexas foram extintas, enquanto outras simples foram mantidas durante milhares de anos. Para algumas espécies, é mais vantajoso possuir uma estrutura simples de organização, como aponta Darwin em A Origem das Espécies:

Na verdade, a Seleção Natural, ou a sobrevivência do mais apto e mais forte, não leva necessariamente a um desenvolvimento progressivo, apenas se apodera das variações que se apresentam e que são úteis a cada indivíduo nas relações complicadas de sua existência [...] em virtude de condições de existência muito simples, uma alta organização passa a ser inútil e até mesmo desvantajosa porque, sendo frágil, degenerar-se-ia mais facilmente e também de forma fácil seria destruída (2005, p. I89-I90).

Darwin também escreve que nem tudo é mantido porque exerce alguma função ou proporciona algum benefício, o que também diferencia o seu pensamento do de Durkheim. Inicialmente Darwin defendeu em A Origem das Espécies que toda estrutura biológica possui uma função e foi mantida no decorrer da evolução porque de alguma maneira contribuiu para a sobrevivência da espécie, assim como Durkheim 
5."I had not formerly sufficiently considered the existence of many structures which are neither beneficial nor injurious; and this I believe to be one of the greatest oversights as yet detected

in my work"; "I was not able to annul the influence of my former belief, then widely prevalent, that each species had been purposely created; and this led to my tacitly assuming that every detail of structure, excepting

rudiments, was of some special though unrecognized service" (BROOKE, 2003, p.

6. "Was Max Weber a Selectionist in Spite of Himself?" (RUNCIMAN, W. G., 2001). acreditava que toda estrutura social servia para garantir a existência da sociedade. No entanto, na obra A Origem do Homem, Darwin se corrige:

Eu não tinha previamente considerado suficientemente a existência de muitas estruturas que não são beneficiais ou prejudiciais; e isso eu acredito ser um dos grandes descuidos já detectados em meu trabalho. Eu não fui capaz de anular a influência da minha antiga crença, na época largamente prevalente, de que cada espécie foi criada propositalmente, e isso me levou a tacitamente assumir que cada detalhe da estrutura, exceto rudimentos, possuía alguma função especial, apesar de não reconhecida (tradução nossa, BROOKE, 2003, p. 198$) .5$

Assim como Darwin, Weber não apoiava a ideia de progresso. É curioso como Weber, que entre Marx e Durkheim era o mais contrário à aplicação do evolucionismo à sociedade, tinha muitas vezes ideias mais próximas às de Darwin do que os outros dois $^{6}$. Ele criticava a tentativa de Marx de encontrar o "motor da história", pois defendia que não havia uma explicação única para os acontecimentos passados, que eram influenciados por múltiplos fatores. Ironicamente, para Weber, o método materialista de Marx possuía resquícios de influências religiosas, uma vez que supõe a existência de um propósito superior no decorrer da história, assim como a teologia acredita que Deus comanda o curso da humanidade em direção ao bem comum. Darwin também defendia que, por trás da ideia de progresso, está a crença de que existe um plano divino que orienta a evolução das espécies; no entanto, a evolução não é racional, ela não segue uma direção, mas acontece ao acaso. Weber, por sua vez, insistia que "Paradoxo, ironia e consequências imprevistas [...] estavam sempre presentes, além de conflitos incessantes e sem direção" (Kalberg, 20Io, p. 28).

\section{Transformação ou seleção}

Para Weber, assim como para Marx e Darwin, o conflito é uma das chaves para entender as mudanças históricas. Por isso, ele concentra muitos de seus estudos nas formas de dominação, procurando explicar como a visão de mundo de grupos socialmente selecionados passa a orientar as atitudes subjetivas de todos os indivíduos de uma sociedade. Diferentemente de Marx, que defendia que os modos de produção determinavam a maneira de pensar dos homens, Weber via um encaixe entre um 
modo de produção e um modo de pensar já existentes, sem que um tenha feito o outro surgir. Ele chama de materialismo histórico ingênuo a concepção "segundo a qual 'ideias' como essa [as do espírito capitalista] são geradas como 'reflexo' ou 'superestrutura' de situações econômicas" (Weber, 2007, p. 48). Pode-se dizer, então, que a explicação de Marx é transformista, enquanto a de Weber é selecionista. Marx defendia, por exemplo, que os males do capitalismo, como alienação, exploração, desperdício e ineficiência se tornariam tão graves "a ponto de criar as condições subjetivas para uma revolução comunista” (Elster, I989, p. I79). Portanto, o ambiente seria capaz de provocar o aparecimento de novas características nos indivíduos. Já Weber oferece uma explicação selecional em A ética protestante e o “espírito” do capitalismo, segundo a qual as variações existem a priori e são selecionadas ao se adequarem a um ambiente. A ética protestante já existia, de maneira independente do “ambiente” capitalista, todavia, quando essa ética apareceu inserida no contexto capitalista, ela foi selecionada e, ao longo do tempo, passou a predominar na maioria dos indivíduos, perdendo sua conexão com a religião e formando o espírito do capitalismo. Assim, "esse 'espírito' do capitalismo pode ser entendido como puro produto de uma adaptação" (Weber, 2005, p. 64) e "teve de travar duro combate contra um mundo de forças hostis" (Weber, 2005, p. 49) para se estabelecer.

\section{Considerações finais}

As ideias de Darwin, assim como as de Marx, Durkheim e Weber, deram margem, na história, a uma série de diferentes interpretações. Muitas vezes, essas interpretações se tornaram ideologias que custaram muitas vidas, como no caso da eugenia nazista e da repressão do partido comunista na antiga União Soviética. A aplicação da teoria da evolução por seleção natural às sociedades humanas, o chamado darwinismo social, também gera até hoje muitas discordâncias e implicações antiéticas. Como foi dito, é preciso levar em conta a peculiaridade do homem entre os outros animais antes de transformar as leis que regulam a natureza em explicações da evolução e das relações humanas. Porém, fazer conexões entre as ideias dos clássicos da sociologia e as do maior clássico da biologia nem sempre tem consequências desastrosas. Por trás de teorias e conceitos de diferentes áreas, podem existir os mesmos princípios epis- 
temológicos e metodológicos. Por isso, estabelecer relações é uma eficaz ferramenta interpretativa. Darwin, Marx, Durkheim e Weber, muitas vezes, seguiram os mesmos pressupostos em suas análises históricas e chegaram a conclusões semelhantes sobre as mudanças que ocorrem na natureza e na sociedade humana. Com base nas interseções feitas entre esses teóricos, pode-se perceber que existem diversas perspectivas sobre a história natural e social que variam quanto ao foco dos estudos, as leis que procuram explicar como transcorre a história, a visão de progresso e os mecanismos de mudança. A discussão de questões dessa natureza contribui para o esclarecimento de metodologias de pesquisa histórica na Biologia e na Sociologia, enriquecendo o ensino de ambas as áreas no meio acadêmico ao favorecer a construção de visões transdisciplinares e críticas.

\section{Referências}

BOURDIEU, P.; CHAMBOREDON, J. C.; PASSERON, J. A profissão de sociólogo. Tradução Guilherme João de Freitas Teixeira. Petrópolis: Vozes, I999.

BROOKE, J. H.; HODGE, J. (Ed.); RADICK, G. (Ed.) Darwin and Victorian Christianity. The Cambridge Companion to Darwin, 2003, p. I92-2II.

CAPONI, G.; DOMINGUES, H. M. B. (Org.); Sá, M. R. (Org.); PUIG-SAMPER, M. A. (Org.); GUITIÉRREZ, Rosaura Ruiz (Org.). El darwinismo y su otro, la teoria transformacional de la evolución. Darwinismo, Meio Ambiente, Sociedade. São Paulo: Via Lettera; Rio de Janeiro: MAST, 2009, p. I77I84.

COLP, R. Jr. The myth of the Darwin-Marx letter. History of Political Economy v. I4:4, p. 46I-482, I982.

DARWIN, C. A Origem das Espécies. Tradução John Green. São Paulo: Editora Martin Claret, 2005.

DURKHEIM, É. As Regras do Método Sociológico. Tradução Paulo Neves, revisão da tradução Eduardo Brandão. São Paulo: Martins Fontes, 2007.

ELSTER, J. Marx Hoje. Tradução Plínio Dentzien. São Paulo: Paz e Terra, I989.

GERRATANA, V. Marx and Darwin. New Left Review, 35 (I974), p. 6o-82.

GOULD, S J. Darwin e os Grandes Enigmas da Vida. Tradução Maria Elizabeth Martinez. São Paulo: Martins Fontes, I999.

KALBERG, S. Max Weber: uma introdução. Rio de Janeiro: Jorge Zahar, 20 Io. 
SCHALL, B. DARWIN E MARX, DURKHEIM E WEBER: RELAÇÕES ENTRE A FORMA DE PENSAR EVOLUÇÃO NA BIOLOGIA E NA SOCIOLOGIA

MARK, K.; FERNANDES, F. (Org.). Trabalho alienado e superação positiva da autoalienação humana (Manuscritos econômicos e filosóficos). K. Marx, F. Engels - História. São Paulo: Ática, I983.

QUINTANEIRO, T.; BARBOSA, M. L. O.; OlIVEIRA, M. G. M. Um Toque de Clássicos. 2. ed. Belo Horizonte: UFMG, 2002.

RUNCIMAN, W.G. 200I. Was Max Weber a Selectionist in Spite of Himself? Journal of Classical Sociology. 200I, p. I- I3.

WEBER, M. A ética protestante e o "espírito" do capitalismo. Tradução José Marcos Mariani de Macedo, edição Antônio Flávio Pierucci. São Paulo: Editora Schwarcz, 2005. 